\title{
LA TRANSFORMACIÓN DEL PAISAJE EN LA SIERRA POBRE DE MADRID. INFLUENCIA DE LA AGRICULTURA Y GANADERÍA EN LA EXTINCIÓN LOCAL DE LOS PINARES
}

\author{
POR \\ FERNANDO PARDO y LUIS GIL
}

\section{Introducción}

El paisaje actual es imposible de entender sin tener en cuenta la acción humana, que ha condicionado la presente distribución de los tipos de vegetación y provocado cambios irreversibles, como los debidos a la extinción local de especies. Por ello, la composición, la dinámica y el funcionamiento de los actuales sistemas forestales son diferentes a los primitivos. Se acepta que las montañas son los últimos lugares modificados por el hombre, al presentar mayor superficie boscosa y ecosistemas más maduros (Ruiz de la Torre, 1990); también por ser posible encontrar reductos de una situación anterior (Fillat, 1993). No obstante, desde la antiguedad, pero en el último milenio con una mayor continuidad y extensión, las altas sierras también fueron transformadas, destinándolas a proporcionar pastos estivales para los ganados; el fuego, seguido del pastoreo, han sido los principales agentes modeladores.

La sociedad urbana, hoy predominante, ha favorecido una visión romántica del mundo rural tradicional, que exculpa una intensa sobreexplotación del medio natural. También olvida la dureza y las mi-

Fernando Pardo y Luis Gil. Depto. de Silvopascicultura. E.T.S. de Ingenieros de Montes. 
serias del agricultor ${ }^{1}$, cuyos únicos recursos disponibles eran los del entorno, que se utilizaban para satisfacer necesidades inmediatas.

La emigración a las ciudades, iniciada en los años sesenta, determinó el abandono de los denominados «eriales a pastos» e, incluso, de campos antes cultivados. En esta nueva situación, el terreno históricamente deforestado tiene dificultades para recuperar el bosque original. Sin considerar la pobreza de unos substratos erosionados que incrementan los rigores del clima, cuando no hay árboles, no se forman los propágulos que permiten la recuperación del bosque. Esta falta de una cubierta arbórea propició, entre otras razones, una intensa etapa de repoblación forestal, que abarca desde 1940 a 1980 85 , periodo en el que se produce la transferencia de las competencias forestales a las Comunidades Autónomas. La actividad se extendió a unos tres millones de hectáreas, siendo los pinos las especies más utilizadas. La proliferación de estos «nuevos pinares» ha sido atribuida por ciertos autores (Sanz, 1985) a las exigencias del mercado y del desarrollo económico; llegándose a señalar que la cobertura vegetal creada no tiene nada, o muy poco, que ver con las formaciones vegetales originales (Fernández Galiano, 1990). Sin embargo, los pinares son bosques ignorados (García Latorre y García Latorre, 1996), pues su ausencia es el resultado de transformaciones ecológicas regresivas que no han sido apreciadas.

El presente estudio * se centra en un sector de montaña del Sistema Central español sometido a una intensa explotación ganadera y agrícola. El área posee un gran interés geobotánico por ser el límite meridional de la distribución ibérica de numerosas especies de carácter templado, reflejo de un clima favorable a la vegetación, aunque también incorpora elementos mediterráneos genuinos (Hernández Bermejo y Sáinz Ollero, 1978). Sobre la base del registro paleopolínico e histórico, se analizan los cambios en su paisaje. Las fuentes más

* Trabajo desarrollado dentro del proyecto «Estudio y seguimiento del Hayedo de Montejo de la Sierra», financiado por la Comunidad de Madrid.

1 Joaquín Costa las enunciaba en 1911: "es todavía Agricultura del siglo xv: Agricultura del sistema de año y vez, por falta de abonos minerales; de la rogativa por falta de riego artificial; del transporte a lomo, por falta de caminos vecinales; Agricultura del arado romano, del gañán analfabeto, del dinero al 12 por 100 , de la bárbara contribución de Consumos, de la mezquina cosecha de cinco o seis simientes por cada una enterrada, del cosechero hambriento, inmueble, rutinario, siervo de la hipoteca y del cacique». 
antiguas utilizadas, con referencias puntuales a sistemas forestales, corresponden a los siglos XII y XIII. También se han consultado otros documentos de siglos posteriores, los cuales permiten aproximar las modificaciones en su fisonomía.

\section{Área de estudio y vegetación arbórea}

La denominada Sierra Pobre se localiza en el cono norte de la Comunidad de Madrid. Forma parte de Somosierra y Ayllón, macizos montañosos de los que se separan en dirección sur una serie de alineaciones menores (figura 1). El estudio se ha centrado en la mitad nororiental de esta comarca, de mayor interés por su carácter montañoso y por coexistir un conjunto de especies vegetales ausentes o poco abundantes en el resto del Sistema Central. Este área comprende los municipios de Somosierra, Montejo de la Sierra, La Hiruela, Puebla de la Sierra, Prádena, Horcajuelo, Horcajo, Robregordo, Madarcos y La Acebeda, cuyos términos suman casi 25.000 hectáreas, algo menos de la mitad de la extensión de la Sierra Pobre (unas 60.000 hectáreas).

La elevada altitud de la zona, su acentuada orografía y el clima, demasiado frío y no excesivamente lluvioso, han limitado el desarrollo económico de la Sierra Pobre (no en vano ha adquirido este calificativo). Por estas razones tanto la agricultura como las comunicaciones se han visto notablemente dificultadas. La comarca ha estado abocada a una economía de subsistencia con un predominio de la ganadería. El carácter autárquico perduró hasta los años sesenta, en los que se abandonó una agricultura desarrollada en condiciones poco propicias. Las necesidades básicas de cereales se aseguraban gracias al cultivo de plantas tan resistentes como el trigo tremesino o el centeno ${ }^{2}$.

Los melojares (bosque submediterráneo de Quercus pyrenaica) y los pinares albares (Pinus sylvestris ) constituyen la vegetación potencial predominante en los fitoclimas nemoromediterráneo genuino (VI(IV)2) y oroborealoide subnemoral (VIII(VI)) respectivamente

2 Fernández (1966) señala como frecuentes las épocas de hambre motivadas por las malas cosechas, dando lugar a episodios de peste, entre los que destaca el acaecido en 1599 . 


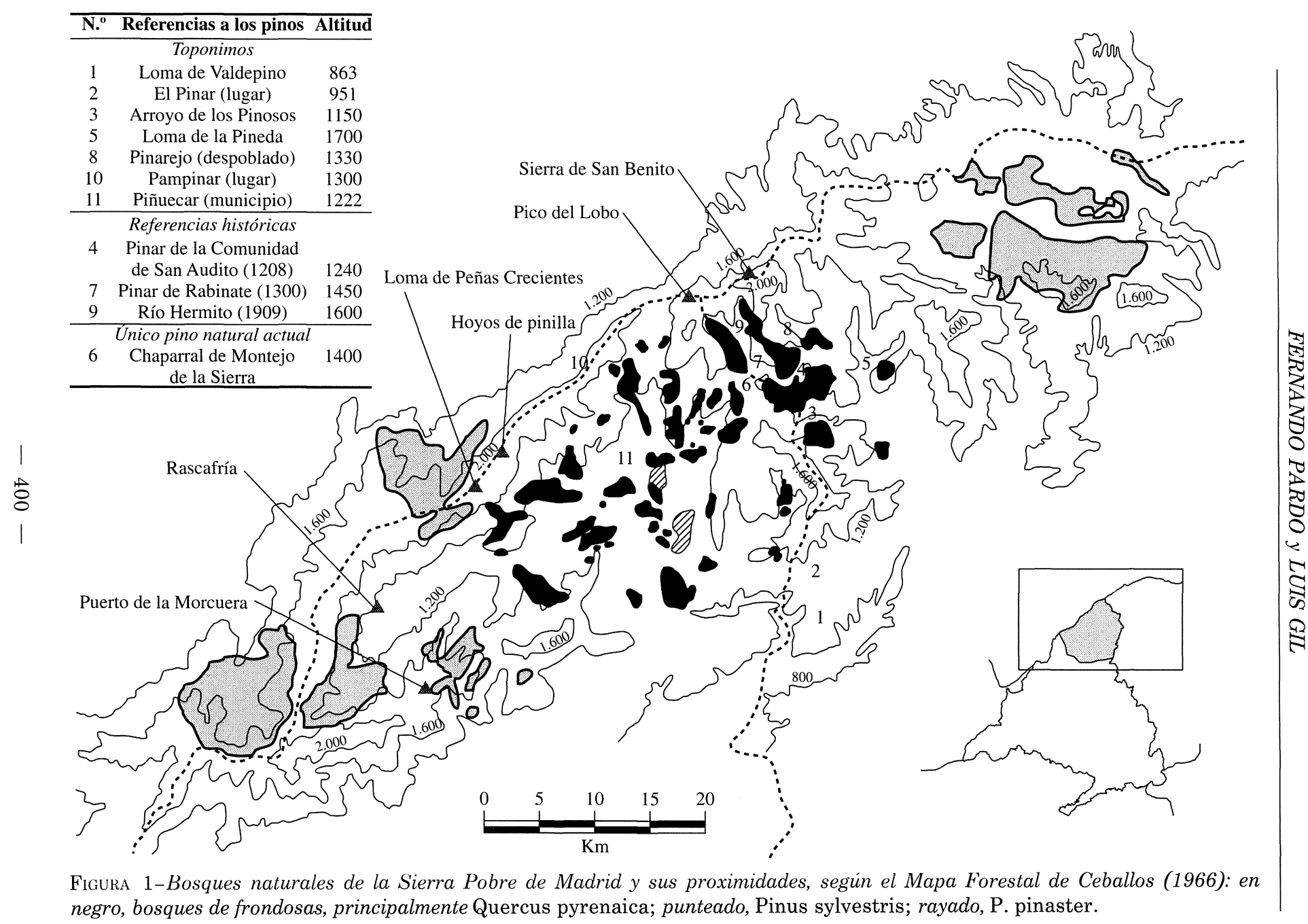




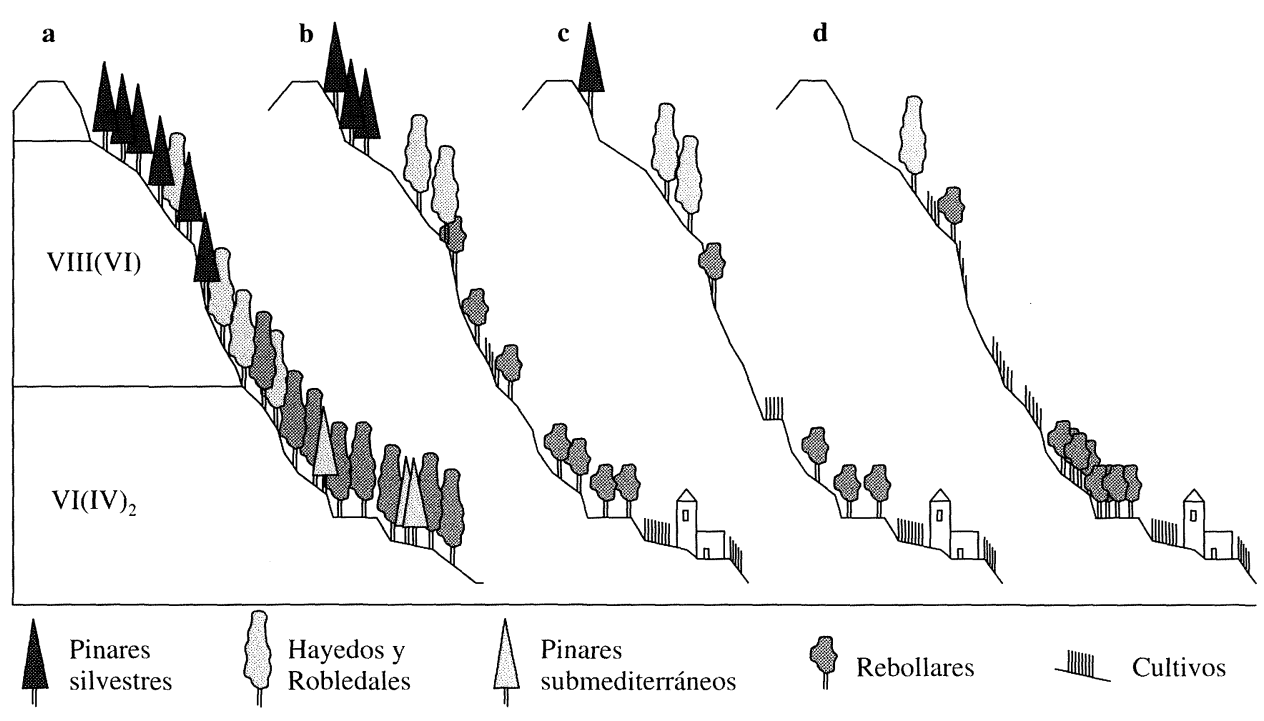

Figura 2-Evolución de la vegetación de la Sierra Pobre según gradiente altitudinal. a) bosque primitivo; b) primera etapa de desarrollo agricola-ganadero (1086-1366); c) Apogeo de la ganaderia lanar (1366-1837); d) Segunda etapa de desarrollo agricola-ganadero (1837-actualidad). Se indican también los límites aproximados de los pisos fotoclimáticos de Allué (1990).

(Allué, 1990) ${ }^{3}$. La presencia actual en la zona de elementos residuales templados, como el haya (Fagus sylvatica), el roble albar (Quercus petraea) o el avellano (Corylus avellana), apoyan la existencia de un primitivo cinturón altitudinal intermedio de bosque templado (hayedo, robledal o mixto), al menos en las vertientes de umbría (figura 2.a) como indican, por otro lado, los análisis polínicos (Costa et al. 1990; Gil García, 1992; Franco, 1995). Además de las zonas potenciales de pinar ( $P$. sylvestris) otros lugares debieron contar con especies de este género. La principal sería el pino resinero ( $P$. pinaster) que, dentro del área de estudio, es una especie colonizadora de ámbi-

3 El oroborealoide subnemoral (VIII(VI)) es un fitoclima caracterizado por una precipitación anual superior a los $950 \mathrm{~mm}$ y una temperatura media del mes más frío (Tf) menor o igual a $4^{\circ} \mathrm{C}$. El nemoromediterráneo genuino (VI(IV)2) con Tf menor a los $7,5^{\circ} \mathrm{C}$ y precipitaciones superiores a los $750 \mathrm{~mm}$. Tanto al norte como al sur está presente un Fitoclima nemomediterráneo genuino con precipitación inferior a $750 \mathrm{~mm}$ (VI(IV)1). 
to ecológico similar al del melojo en su tramo inferior; tampoco sería descartable la presencia de $P$. nigra entre la vegetación primitiva. Los pinos son en general especies frugales, heliófilas y pioneras, cuya permanencia está ligada a la existencia de perturbaciones, por ejemplo el fuego o la tala, que favorecen el rejuvenecimiento edáfico a favor de las pendientes, abundantes en la comarca por su abrupta topografía; también a condiciones edáficas particulares como litosuelos o perfiles con texturas gruesas que apenas almacenan agua y cuya evolución está impedida por el clima.

A estas especies arbóreas habría que añadir al menos otras dos, ampliamente extendidas en la actualidad: el fresno (Fraxinus angustifolia) y el acebo (Ilex aquifolium). La primera es un elemento submediterráneo que requiere cierto grado de humedad edáfica y que en ocasiones se mezcla con el melojo. El acebo es propia de melojares húmedos y está asociada a otras especies templadas como el haya o el roble albar. Ambas han tenido una gran importancia en el aprovechamiento pecuario de los montes por la utilización de su ramón.

\section{El paisaje según los análisis polínicos}

Los estudios paleopolínicos realizados en las Sierras de Guadarrama, Somosierra y Ayllón, especialmente en las dos últimas ${ }^{4}$, hacen posible aproximarse a los paisajes antiguos. Han sido escogidas seis secuencias por ser cercanas a la Sierra Pobre, por su antigüedad o por tener dataciones (figura 3). En todos los casos es evidente el descenso del polen arbóreo, pasando de cifras superiores al 50 por 100 en la base, hasta valores del 10 al 20 por 100 en la superficie. La disminución afecta principalmente al polen de Pinus, excepto en San Benito, sondeo situado en la vertiente septentrional de Ayllón, a $1.440 \mathrm{~m}$ de altitud (Ruiz del Castillo, 1993), donde es el porcentaje de polen de Quercus el que decae bruscamente. La secuencia de mayor antigüedad es la registrada en Rascafría (Franco, 1995), a 1.113 $\mathrm{m}$; proporciona la imagen de un terreno arbolado desde los 8.000 a los 4.000 años BP, con un episodio de deforestación registrado a los $190 \mathrm{~cm}$ de profundidad, unido a la presencia de carbones.

4 Franco (1995) revisa los trabajos llevados a cabo en estas tres sierras, los cuales suman un total de 25 secuencias, incluidos los dos realizados por esta autora. 

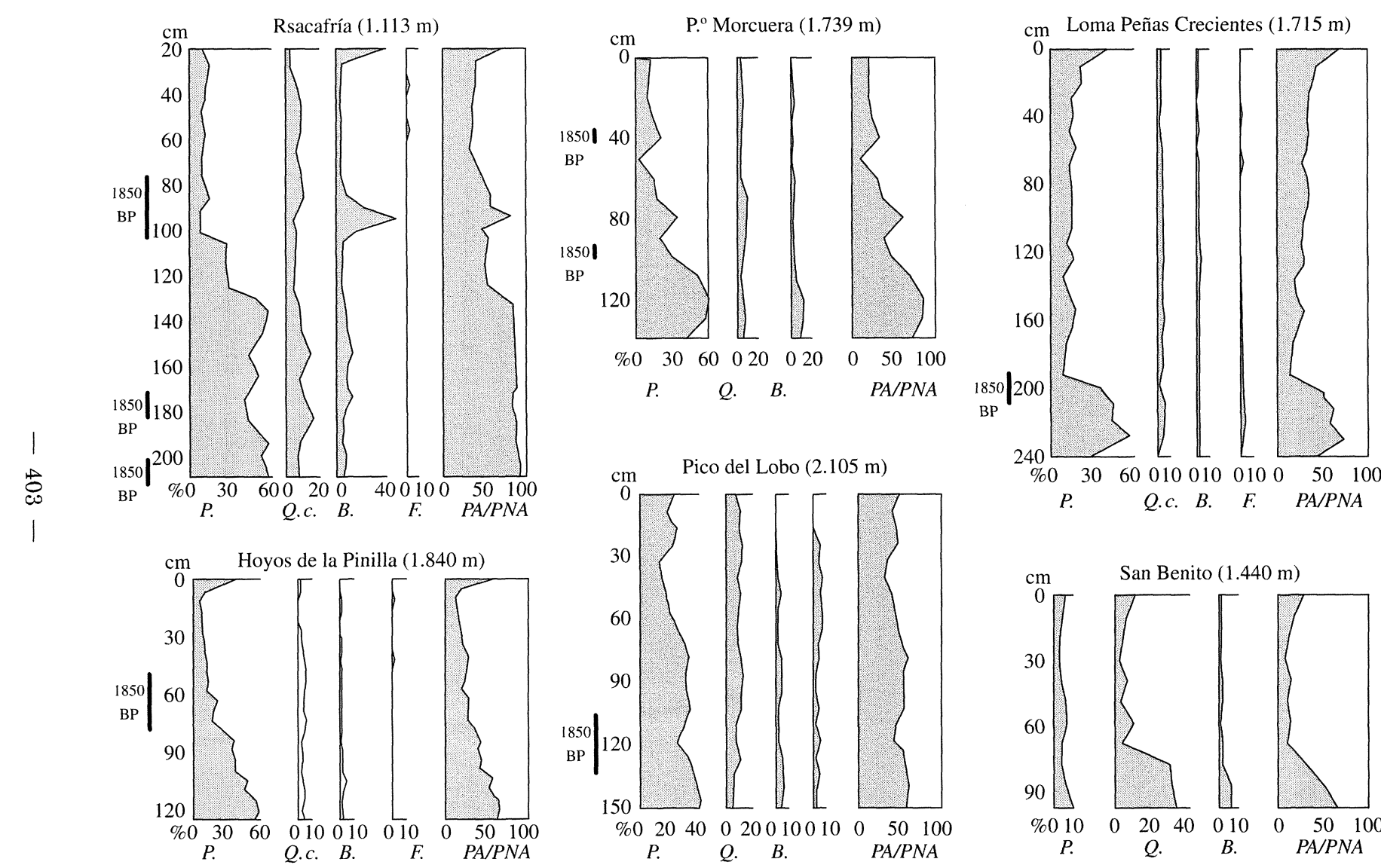

Figura 3-Diagramas polínicos de los principales taxones arbóreos de 6 estaciones seleccionadas. Los asteriscos indican la presencia de carbones en distintos niveles de los sondeos. Este factor solo ha sido estudiado en las estaciones de Rascafrí, Puerto de la Morcuera y San Benito. P: Pinus, Q. c .: Quercus tipo caducifolio, B: Betula y F: Fagus. 
Llama la atención que las formaciones dominantes en todos los diagramas, excepto en el de San Benito, sean los pinares (figura 3) que hoy están ausentes en dos de ellos, Pico del Lobo y San Benito (figura 1). Los bosques de alta montaña de Pinus sylvestris, en la actualidad, faltan de modo natural en toda la Sierra Pobre. El segundo lugar lo registra el polen de Quercus caducifolios. Ruiz del Castillo (1993) no los diferencia del de los perennifolios, pero por la altitud de los yacimientos analizados por este autor (San Benito, $1.440 \mathrm{~m} \mathrm{y}$ Morcuera, $1.739 \mathrm{~m}$ ), se puede aceptar que la mayor parte del polen de Quercus se corresponderá con caducifolios. Betula se mantiene constante y con bajos niveles, aunque en Rascafría presenta picos que pueden estar relacionados con una invasión local y momentánea, lo cual está de acuerdo con el carácter pionero de esta especie. Fagus adquiere cierta importancia en una de las dos secuencias de Ayllón, la localizada en el Pico del Lobo (Gil García, 1992), mientras que su polen aparece puntualmente en tres de los diagramas de Guadarrama.

Los episodios de deforestación recogidos tienen lugar en torno a los 3.000 años de antigüedad en el Puerto de La Morcuera y Rascafría y, en ambos casos, se da la aludida presencia de carbones. En otros diagramas, de menor antigüedad, también hay pérdida de polen arbóreo en momentos más recientes y, en ciertos casos, tal reducción coincide con la aparición de registros de cereal. La deforestación continuó con escasas interrupciones en Hoyos de Pinilla y Morcuera, mientras que en Peñas Crecientes hay un muy ligero pero constante aumento del polen arbóreo hasta la actualidad. En Rascafría y en el Pico del Lobo se observa un nuevo descenso del polen arbóreo en torno al $1.000 \mathrm{BP}$.

La evolución polínica de los taxones arbóreos en los seis diagramas muestra distintos momentos de deforestación en los últimos 3.000 años; sin fácil justificación en razones climáticas, pues no hay una sincronía en las etapas de reducción del polen arbóreo en las distintas secuencias. Tal deforestación contrasta con el claro dominio del bosque sobre otros tipos de vegetación en los milenios anteriores. La disminución del bosque aparece asociada a incendios (presencia de carbones) o al cultivo (pólenes de cereal). Entre los árboles, el tipo polínico con mayor pérdida de efectivos en cinco de los seis yacimientos analizados es Pinus, mientras Quercus t-caducifolio se man- 
tiene o sólo experimenta ligeras oscilaciones. Cabe recordar que la reducción del polen de Quercus no va acompañada necesariamente de la pérdida del melojar en el caso de Quercus pyrenaica, sino en su transformación en un rebollar ${ }^{5}$, o monte bajo aprovechado para leñas o carboneo.

\section{Los cambios del paisaje en el último milenio}

La existencia de documentos que reflejan las actividades de transformación de la cubierta vegetal se limitan al último milenio. En el año 1086, cuando se reconquista el reino de Toledo, se repuebla la comarca en torno a Buitrago, núcleo que será el centro administrativo de la Comunidad de Villa y Tierra de su nombre. Los cambios del paisaje a partir de este momento están relacionados con los acontecimientos históricos, pudiéndose diferenciar tres grandes etapas.

El primer periodo se corresponde con la formación de la Comunidad de Villa y Tierra de Buitrago (1086-1366) y podría ser calificado como de desarrollo agrícola-ganadero. En el privilegio dado por Alfonso VI, en 1134, se advierte de la falta de atractivo y de aptitud de la comarca para la agricultura (era muy áspera para el cultivo de las mieses y las viñas), pero se insta a los colonos a que cultivasen los campos para que sean aptos para su sustento (Fernández, 1980). Esta época destaca por una menor limitación a la roturación de tierras, sólo las propias del medio geográfico y las derivadas de tener que reservar un espacio para los ganados de labor (dehesas boyales). El segundo periodo, de casi cinco siglos, se inicia y termina con el Señorío de Buitrago (1366-1837). En él se restringen los cultivos y se orienta la economía hacia la ganadería trashumante, pues el Señor de Buitrago y el resto de los nobles de la comarca son grandes propietarios de ovejas merinas (Grupo 73, 1973). En la tercera etapa tiene lugar

${ }_{5}^{5}$ La tala periódica, cada cierto número de años, para aprovechamiento de leñas o para hacer carbón, permite que las formaciones de Quercus pyrenaica se puedan mantener secularmente en un estado inmaduro, con predominio de pies vegetativos que apenas producen polen. $Q$. pyrenaica posee al menos dos nombres vulgares: melojo y rebollo. La denominación vulgar de rebollo es de origen incierto, pero probablemente derivado del latín pullus; 'retoño' (Corominas y Pascual, 1981), término que aludiría con precisión a la capacidad de esta especie para rebrotar intensamente de cepa o de raíz. En zonas donde no existen otros Quercus caducifolios también se le llama roble.

$$
-405-
$$


un nuevo ciclo de roturaciones y deforestación tras la abolición del Antiguo Régimen; la desamortización civil y eclesiástica y la desaparición de la Mesta irán unidas al incremento demográfico ${ }^{6}$. La secular escasez de labrantíos condujo a que los patrimonios de las denominadas manos muertas y los privilegios de la Mesta se vieran afectados.

Los cambios del paisaje afectaron prácticamente a todo el territorio, aunque con distinta intensidad y periodicidad. Las formaciones de pinar, presentes en todos los registros paleopolínicos, tendrán un destino bastante diferente al de las frondosas. En ello van a intervenir tanto factores biológicos como históricos.

\section{Presencia y extinción del pinar}

Tras la formación de la Comunidad de Villa y Tierra de Buitrago, los reyes tratan de fomentar la instalación de colonos, para lo cual les conceden "Privilegios" si se asientan en la zona. En el otorgado por el rey Alfonso VI, en 1134, ya citado, se habla de "selvas", "montes" y "campos" por lo que, sin establecer analogías con dichos términos, podemos admitir que existía un mosaico de paisajes: bosques en diferentes grados de evolución, eriales (matorrales y pastizales) y campos de cultivo. Ni en este texto, ni en el Fuero Real de Buitrago de 1294 (Fernández, 1980), se mencionan las especies arbóreas presentes.

La existencia histórica de los pinares en la Sierra Pobre se conoce por varios documentos. Uno de ellos data del año 1208 (González, 1960; Sáez, 1991); describe la donación por Alfonso VIII de una serie de términos, localizados cerca de La Hiruela -al nordeste de la comarca de Buitrago-, a la comunidad de San Audito. En la actualidad sólo se conserva un topónimo, Santuy, derivado del anterior nombre. El texto muestra la continuidad histórica de un pinar ${ }^{7}$ den-

6 El número de habitantes pasa de 7.000 en la época del Catastro de Ensenada a más de 9.600 en la mitad del siglo xIx. Aumento que va relacionado con el descenso de la ganadería en algunas localidades; así en la villa de Buitrago se cuentan 64.000 cabezas lanares en 1752 por unas mil en 1848 (Grupo 73, 1973).

7 La traducción del documento dice: «dono, cedo, concedo... ...las casas y la iglesia de San Audito... ...con los ríos y las fuentes, con los montes, con los bosques y el pinar, con los prados y las huertas, con las tierras cultivadas e incultas... ...para que libre y absolutamen-

$$
-406-
$$


tro de los límites otorgados; éstos, según el documento, se sitúan entre el Cerro de la Calahorra y los ríos Berbellido y Jarama. Además, cita los usos del territorio: agricultura, ganadería y explotación del bosque, y señala el uso mancomunal del espacio forestal por los habitantes de la comunidad religiosa y las de Buitrago y Sepúlveda ${ }^{8}$.

Un segundo documento que recoge la presencia de pinares es un privilegio concedido por el rey de Castilla al concejo de El Cardoso (Guadalajara) en el año 1300. En el texto se dice: ... que el Concejo de Sepúlveda hobo dado a los homes buenos del Cardoso... el rio de Jarama como tien desde el arroyo Frio hasta el canisus del pinar del Rabinate (Anónimo, 1833). Los dos topónimos citados en el documento, Arroyo Frío y Rabinate, permiten localizar este pinar en la ladera opuesta al Hayedo de Montejo.

Un tercer diploma referente a pinares fue emitido en 1186 en Buitrago (González, 1960) y aunque se refiere a Sepúlveda se extiende a la zona de estudio. En él se otorgan derechos de pastos y leñas a favor del monasterio de Sacramenia, que se pueden ejercer in terminis, montibus, nemoribus et pinaris Septempublice. Expresión que permite aceptar una generalización de los pinares en el paisaje, tanto en la llanura como en la sierra; lo que será confirmado por los documentos mencionados y por el fuero de esta Comunidad ${ }^{9}$ (Sáez, 1953). El interés de la protección del área forestal serrana de Sepúlveda (Somosierra y Ayllón) nos indica la existencia de una presión que pudo poner en peligro a estas especies, como consecuencia de la explotación que los ganaderos segovianos hicieron de la vertiente septentrional de la sierra antes de la Reconquista (Pastor de Togneri, 1973), cuya extensión a las vertientes meridionales fue el siguiente paso.

te... ...podáis apacentar las ovejas y todos vuestros animales por toda la sierra y también cortar indiferentemente la leña y cuanto queráis, con los hombres de los concejos de Sepúlveda y de Buitrago... »

8 En los primeros tiempos de la Reconquista, la Sierra Pobre perteneció a la Comunidad de Sepúlveda; Buitrago se separa en el 1086, pero mantendrá ciertos derechos como el señalado en el documento. Posteriormente, seguirán permaneciendo bajo la jurisdicción de la Comunidad de Sepúlveda gran parte de la cuenca alta del Jarama, hoy perteneciente a la provincia de Guadalajara y varios lugares de la de Madrid (Somosierra y Robregordo).

9 El fuero que data de 1300 consagra varios títulos a la defensa del pinar y de otras especies arbóreas: «Del que fiziere resineras, o fiziere rayos [astillas], o echare pino verde de raiz». Los árboles de montaña aparecen con cierta exhaustividad en el denominado «De los arboles cortar de lla sierra»: «otrossi, a qual omne quiere que fayaren cortan do faya, o mostaio, o pino, o povo, o nieço, o maello, o salze gatiello, o robre, o azevo....» 
Desde el siglo xIV, hasta el xx, no conocemos menciones a los pinos en la zona. Madariaga (1909) sitúa en el Hayedo de Montejo la cita del único pino silvestre que se conserva en la actualidad. Este autor también señala la presencia de más pinos mezclados entre hayas unos kilómetros al norte, en el río Hermito, lugar en el que hoy sólo se conservan las hayas. También recoge la existencia de tocones de pino en el actual despoblado de Pinarejo (figura 1), los cuales eran arrancados y usados por vecinos de El Cardoso (Guadalajara); dicho lugar, situado en el término de Bocígano, era aldea de Sepúlveda en el censo de 1594 (Martínez Díaz, 1983); su nombre constata un pinar degradado en el momento de la gestación del topónimo.

La pasada existencia de pinares también viene avalada por otros topónimos (figura 1). La mayor parte de ellos son de origen cristiano y datan como mucho de la Reconquista (Fernández, 1980), por lo que es admisible una distribución extensa del área del pinar durante esta época. El mayor número de localizaciones se da en las zonas de alta montaña, siguiendo el límite entre las provincias de Madrid y Guadalajara, en altitudes que oscilan entre 1.500 y 2.000 metros. No solamente existieron las masas de pino silvestre, sino también de pino resinero (Pinus pinaster) y quizás de pino negral ( $P$. nigra). Al siglo xIx llegaron varios rodales de $P$. pinaster, cuya localización es posible conocer por estar recogida en los trabajos topográficos del Instituto Geográfico y Estadístico. Los mapas relativos a los términos de Paredes de Buitrago y Serrada de la Fuente, realizados en la segunda mitad del siglo XIX, constatan la presencia de monte alto de pino que nos llega hasta la actualidad; estos pinares se incrementarían a otros municipios colindantes como el de Buitrago por repoblación forestal 10 .

La ausencia de menciones a los pinos desde los siglos XIV al XIX es difícil de explicar. Existen varias hipótesis que podrían justificar

10 La serie denominada «Trabajos topográficos» está realizada, por término municipal, a escala 1:25000 y recoge diversa información, entre la que se incluye el uso del suelo. Los mapas de Serrada y Paredes, confrontados en el Servicio de Documentación del Instituto Geográfico Nacional, son copias realizadas en 1878 y 1892 respectivamente de originales más antiguos cuyas fechas se desconocen. En el mapa forestal de Ceballos et al. (1966) aparecen tres masas de Pinus pinaster :onsideradas como naturales en el sur de la zona, una de ellas en Buitrago. Sin embargo esta última no tiene origen espontáneo sino que se debe a las antiguas repoblaciónes realizadas dentro del programa de reforestación de la Cuenca del Lozoya. 
tal olvido. En primer lugar porque el polen recogido en los sondeos no fuera local sino regional; sin embargo, el polen de estas especies aparece profusamente en los registros holocenos de ambas mesetas (Costa et al., 1990). Además, cuando los porcentajes de representación superan al 50 por 100 se acepta la procedencia local (Huntley y Birks, 1983). Una segunda razón podría ser la sustitución de los pinares por robledales de manera espontánea, con anterioridad al siglo xIv; hecho que no viene avalado por los análisis polínicos, pues se observa un mantenimiento de los robledales o una disminución paralela a la de los pinares. En tercer lugar, los pinares podían carecer de importancia para el hombre medieval, razón por lo que no se les nombra en los documentos. A este respecto cabe decir que la utilidad de estas especies no está en conservarlas; el beneficio se obtiene tras su apeo, bien sea para la obtención de maderas de sierra o de construcción, de leñas o de pez. Tal acción permitirá en ocasiones cultivar el espacio donde se asientan o dejará hueco al pastizal heliófilo. Como última hipótesis, la falta de referencias de estas especies, podría deberse a la total desaparición del pinar en las primeras etapas de desarrollo agrícola y ganadero; pero se puede afirmar que los pinos seguían presentes en los momentos en que se promulga la regulación de los montes, pues lo muestra su permanencia en el siglo $\mathrm{xx}$, aunque ya de forma residual.

\section{La transformación de los robledales y otras formaciones de frondosas}

El destino de las formaciones forestales más extendidas se puede seguir con más detalle a partir del siglo xvi, gracias al conjunto de documentos normativos sobre el Señorío de Buitrago y sus concejos: las Ordenanzas ${ }^{11}$. Su lectura permite aceptar que las actuaciones an-

11 Gran parte de las ordenanzas están transcritas en la obra «Fuentes para la historia de Buitrago y su tierra», en dos volúmenes, de Matias Fernández (1966), de la cual se extraen las utilizadas en este trabajo. Son de gran interés para el conocimiento de las formaciones forestales de la época las Ordenanzas de Defensa de los Montes (1576), las Ordenanzas sobre Ganados (1582) y las Ordenanzas de Villa y Tierra (1583). La última es la de redacción más antigua; en el Archivo Histórico Nacional existen varias copias, una data de 1568, otra de 1573 , otra sin fecha y finalmente una de 1583, que es la que transcribe íntegramente M. Fernández en su obra y a la cual se alude en el texto. 
teriores habían propiciado una manifiesta alteración del espacio natural 12 .

Las especies arbóreas citadas en diferentes enunciados de las Ordenanzas de Villa y Tierra son: el acebo, la encina, el quejigo, el roble y el fresno; no se nombran ni el haya ni los pinos. Sin embargo, sí encontramos la presencia de hayas en la vertiente septentrional de Somosierra. Un documento de 1474 menciona un rio que dizen Ahedo para referirse al curso de agua que pasa por Cerezo de Arriba. En el año 1479 el Consejo Real manda al concejo de Riaza: non entrades a talar e cortar los robres e ayas en las sierras de la dicha villa [Sepúlveda] (Sáez, 1991). De todas las especies citadas, los robles ${ }^{13}$ serían los más abundantes, tanto por su adecuación a las características climáticas de la zona (figuras 1 y 3), como por ser especies cuya permanencia interesa conservar, dadas sus numerosas utilidades (bellota, ramón, cortezas, carbón, leñas y maderas para la construcción de viviendas, carros y aperos para la labranza).

El destoconado de ciertos árboles se prohibe (que ninguna persona sea osada de sacar de quaxo ni desarraygar en los montes de esta villa e tierra ... ... ningún género de árbol chico ni grande de rroble ni enzina ni quexigo ni fresno). Normativa que otorga ventajas legales sólo a los árboles rebrotadores, pues se legisla su conservación. También evidencian que es necesario prohibir su explotación abusiva, al extraer la cepa o la raíz, motivada por el afán de conseguir un poco más de leña o carbón, mísero benefício puntual que manifiesta su carencia. El bosque se abre para cultivar el terreno o, con más frecuencia en las comarcas montañosas, para aprovechar el pasto que crece entre los árboles dispersos; cuando ya comienzan a escasear se prohíbe talar los robles de más de marco. Otra de las normas de las Ordenanzas muestra una lógica sumisión a la ganadería, pues prohíbe apear o

12 En las Ordenanzas para la Defensa de los Montes (1576) se dice: «... que por la conservación de los montes y ber quán destruida ba esta tierra talándose los montes ques la principal riqueza que se conserben,...»;»...por quanto esta villa de buitrago y su tierra se va disminuyendo en los montes ... ... y a la clara se ha visto y be que haber hecho en ellos carbón y otras talas para madera ... ... hordenaron que de aqui adelante no se haga carbón ...».

13 Por el momento, se hace mención genérica de los robles, incluyendo tanto a la especie submediterránea característica de la zona (Quercus pyrenaica), como al roble templado (Q. petraea). Adoptamos este criterio ya que los análisis polínicos no permiten diferenciar ambos tipos (se refieren únicamente a Quercus caducifolios); lo mismo sucede con los textos antiguos, los cuales tampoco hacen distinción expresa entre ambas especies. 
podar los árboles cuando tuvieran bellota. La leña sólo se podía cortar en los días que se diere lizencia. Se limita la producción de carbón, pues se castiga con mil maravedís si se intenta vender fuera del Señorío. Pero ésta, como otras Ordenanzas serán una y otra vez transgredidas. La venta de carbón a la Villa y Corte de Madrid es una prueba de su incumplimiento; entre los años 1667 y 1709 supuso más de 180.000 arrobas procedentes de la comarca de Buitrago (Bravo, 1993).

Las penas que se imponían por talar el monte eran diferentes según la especie: cortar un acebo se castigaba con 300 maravedís, igual que un roble de más de marco, pero una encina o un fresno lo era con 1.000 maravedís. Considerando tales penas, los árboles más protegidos son los dos últimos, los de mayor interés pecuario. La encina, al ser de hoja perenne, tiene un ramón disponible todo el año y una fructificación mayor, más constante y de mayor calidad que la de los otros Quercus. Las fresnedas proporcionan un ramón excelente, se aclaraban para aumentar el pastizal y se mantenían descabezando los árboles a cierta altura para que el ganado no pudiera destruir los brotes tiernos; pues las varas se empleaban en carretería, mangos de herramientas y otros usos. También destaca el acebo, no en vano los primeros enunciados de las ordenanzas de Villa y Tierra se dedican a la protección de esta especie ${ }^{14}$.

En la copia de las Ordenanzas de Villa y Tierra de 1583 se cita una sola acebeda denominada garganta hermosa. Mientras que en las de 1568, la presencia de acebedas se recoge en otros dos términos: que nadie sea osado de ramonar bacas en las azebedas de garganta hermosa $y$ horcajuelo e montejo. Resulta significativo que en un intervalo de 16 años desaparezca la referencia a las acebedas en dos de los tres lugares. La ausencia se puede atribuir a la pérdida de la formación vegetal; lo que, en algún momento, también afectará a la de garganta hermosa pues tal topónimo no lo hemos detectado en la actualidad ${ }^{15}$.

\footnotetext{
14 Entre otras, se hacían las siguientes prohibiciones: «ramonar bacas ni ningún ganado en las acebedas», "sacar acebo de las dichas gargantas e acebedas fuera de los dias que se diere licencia», "traer en su ato de ganado ovejuno más de doce cabras», "traer vacas en la garganta hermosa en los dias que se da licencia para sacar acebo».

15 Se podría corresponder con el que hoy se conoce como «el gargantón», profundo valle situado en La Acebeda y atravesado por el río del mismo nombre. La alteración del topónimo habría sido paralela a la del paisaje; la pérdida de las acebedas es el resultado de una explotación desordenada para beneficio de la ganaderia del momento, que al ir unido a la pérdida del topónimo permite inferir, una vez más, el incumplimiento de las Ordenanzas.
} 
El castigo a los que prendieran fuego a los montes era especialmente severo, siendo la pena de 2.000 maravedís, a la que había que sumar la correspondiente a cada árbol afectado: que pague el daño que ficiere en lo común de cada pie de encina dos mil maravedis e de cada pie de rroble seiscientos maravedis. La pena es el doble a la estipulada por la corta de estos árboles. Cabe entender un arbolado muy disperso cuando la pena individualiza el número de árboles perjudicados por el fuego.

Durante toda la Edad Moderna se dictaron, por el Señor de Buitrago y por los concejos (siempre con la aprobación del Señor), normas para evitar la deforestación de una superficie cada vez más exigua y degradada; pero que no eran respetadas por unos aldeanos necesitados de algún ingreso. La oligarquía propietaria burlaría sin problemas la pena estipulada. Para Matías Fernández (1980) estos conflictos dejan entrever una lucha a muerte entre ganaderos y labradores, defendiendo cada uno su interés vital; éste se plasma en una explotación abusiva del monte en el caso de los ganaderos, amparados muchas veces por las Ordenanzas 16 .

La pugna agro-pastoral se manifiesta porque está impedido el incremento de la superficie cultivable por las Ordenanzas ${ }^{17}$. Los montes sí se defienden, pero para ser aprovechados por los ganados; destino que tratan de extender a los campos ya dedicados al cultivo, limitando la frecuencia de su siembra ${ }^{18}$ para ampliar el número de

16 «A los labriegos se les restringía la corta de maderas para sus aperos o para las cercas de los huertos, los pastores -al servicio de la oligarquía ganadera- gozaban de mayor libertad, como queda patente en las Ordenanzas de Villa y Tierra: «... que se pue da hacer en los carrascales e montes ... ... corrales de rama de encina o rroble que esten cortadas e comida la hoja sin pena alguna»; «... y el pastor del ganado pueda cortar leña de rroble para la lumbre berde e seca e ... ... aunque sea de encina como esté comida la hoja».

17 "por quanto esta tierra es estéril y conbiene la conservaçión della para el pasto de los ganados ... ... hordenan que de aqui adelante nynguna persona ... ... no sean osados de en trarse en cosa alguna de lo público común desta villa y tierra ny lo rronper ... ... so pena de seyscientos mrs. por la primera vez y por la segunda de mill docientos...»

18 Otra de las normas obliga a que «cada conçejo no pueda tener senbrado mas de un tercio». Regulación que no limita la frecuencia del cultivo por un obligado descanso del terreno por falta de fertilidad, sino para una mayor utilización por la ganadería. Por transgredir estas normas fueron condenados numerosos vecinos e incluso los concejos, como recoge Matías Fernández (1980): en 1533 se condenó a un vecino de Piñuecar «en dos ducados de oro» por no sembrar unas tierras de tercer en tercer año, sino cada año o cada dos años; en 1561, el concejo de la Puebla fue condenado a 30.000 maravedís por sembrar tierras comunales que ya había sembrado en anteriores ocasiones, alegando que era por suma necesidad de pan para viudas y pobres, pese a que no se quitaba el pasto a los ganados de la mancomunidad por que nunca llegaban hasta allí. 
años de barbecho. El labrantío a mediados del siglo xviII (Catastro de Ensenada) suponía bastante menos de la cuarta parte del Señorío.

Con la desaparición del régimen señorial y el declive de la ganadería trashumante, las roturaciones y el carboneo aumentan (Grupo 73, 1973; Fernández Montes, 1990). Los montes huecos serán talados, pero los robles sobrevivirán a través del rebrote de cepas y raíces. Se generalizaron así los característicos montes bajos que pueblan la mayor parte de las dehesas de la zona. Un dato recogido por Madoz (1848) permite cuantificar el lamentable estado en el que llegan estos montes al siglo XIx. En 1847, la inspección de los 227 montes de los 51 pueblos del distrito judicial de Torrelaguna (53 pertenecían a la mancomunidad de villa y tierra de Buitrago) proporciona la cifra de ¡95.420 árboles!; aunque no sea un dato exacto ${ }^{19}$ si es acorde con la situación que describe: el terreno aunque pelado y sin tierra vegetal en muchos puntos de Somosierra que solo son apropósito para pastos.

En la zona de estudio son exceptuadas de la desamortización de Madoz 29 dehesas, que formarán parte del Catálogo de 1862 y serán sometidas a la tutela de los ingenieros de montes de la nueva Administración Forestal; de ellas, 28 estaban pobladas por robles, diferenciándolos entre «roble común» $(Q$. pedunculata $=Q$. robur $)$ y «matas de roble $(Q \text {. tozza }=Q \text {. pyrenaica })^{20}$; solamente una, el Chaparral de Montejo, figuraba como poblada por hayas. La distinción entre matas de roble y roble común responde a categorías de montes establecidas en el informe de la Junta Consultiva de Montes, relativas a la ley de 1 de mayo de 1855 y en el que se identifican especies con ciertos tipos de montes. Los técnicos relacionarían a las «matas de roble» con los montes bajos, que son los montes exceptuados que predominan y asignan los montes huecos como poblados de «roble común», lo que es el caso de las dehesas boyales de Horcajuelo, Madarcos, Robregordo y Somosierra, el monte La Solana, de Montejo, y los cinco montes exceptuados de La Puebla. En la clasificación de los montes

19 Aunque el número de árboles fuera bajo, no incluiría a los brotes vegetativos de las matas de robles, que facilitarían la posterior recuperación de las formaciones de estas especies.

20 No se conoce actualmente la presencia de $Q$. robur en la zona, por lo que su referencia en dicho Catálogo parece incorrecta, tratándose seguramente de bosques de $Q$. pyrenaica formados por ejemplares de mayor porte o en algún caso de $Q$. petraea. 
públicos de 1901 todos los montes aparecen como poblados por $Q$. tozza, a excepción del Chaparral, de Montejo de la Sierra, en el que figura Fagus sylvatica. El catálogo de 1932 ofrece información sobre las superficies de los montes de utilidad pública: las mencionadas dehesas totalizan 3.800 ha, repartidas en 3.344 ha de montes bajos, 265 ha de montes altos y 254 ha de rasos. La superficie forestal llega al siglo xx reducida al 15 por 100 del total de los municipios estudiados.

La poca idoneidad de la comarca, por clima y topografía, impidió el mantenimiento sostenido de las explotaciones. Los aprovechamientos tradicionales, ganadería y agricultura, tienen su fin a mediados de este siglo por falta de rentabilidad, tras lo cual se dió una fuerte emigración (Fernández Montes, 1990). A este abandono del campo y, tras la aparición del butano, de la pérdida del valor de leñas y carbones, le ha seguido el avance del bosque, constituido en su mayor parte por melojares tratados a monte bajo, que aumentarán su talla al dejar de ser aprovechados. Es durante este periodo cuando tiene lugar la mayor parte de las repoblaciones con pinos, resultado del Plan para la Repoblación Forestal de España elaborado en 1939 por Ximénez de Embún y Ceballos. En la zona de estudio fueron realizadas principalmente con pino silvestre; al comienzo de los 60 suman unas 5.000 hectáreas, localizadas en general por encima de los $1.500 \mathrm{~m}$ de altitud. Este cambio de la vegetación ha sido cuantificado en un sector del Macizo de Ayllón (Jiménez Caballero et al., 1995) a través de la elaboración de los mapas de formaciones vegetales utilizando las fotografías aéreas de 1956 y 1984. El territorio estudiado es colindante con la Sierra Pobre madrileña y participa de sus mismas características. En la primera fecha las repoblaciones apenas suman 14 ha, mientras que el predominio es del matorral, 10.386 ha (el 64,0 por 100). En los casi treinta años de intervalo, la suma de los bosques no implantados (diferentes categorías de melojares, encinares o hayedos) pasa de 3.775 a 4.158 ha, el 25,6 por 100 del territorio estudiado (con un incremento del 10,14 por 100 sobre la situación de 1956); las repoblaciones suponen 3.137 ha, un 19,3 por 100 del territorio. Los pinares han generado la denominada «modernización» del monte (Sanz, 1985); pero el cambio ha sido a partir de los matorrales que, aunque reducidos a 7.361 ha, siguen siendo la formación mayoritaria con el 45,3 por 100 . 


\section{Discusión}

Tras la Reconquista, la explotación y transformación del medio alcanza sus máximos, los terrenos son dedicados a distintos usos y la intensidad del cambio dependerá de su distancia a los focos habitados. La zona de cultivos se sitúa en torno a la aldea, no estando alejadas las dehesas comunales (figura 2.b); el aumento de los pastos pudo originar en una primera etapa el descenso del límite altitudinal del bosque, como parece haber sucedido en algunas partes del Pirineo (Villar y García-Ruiz 1977). Los bosques primitivos se vieron afectados de forma desigual y los pinos, ya en formaciones puras o mezcladas, fueron especies incapaces de recuperarse tras una explotación del bosque seguida de pastoreo. Este hecho es bastante frecuente en gran parte de nuestro país, estando recogido en otros lugares del Sistema Central (Luis López, 1987; Mancebo et al., 1993). La tendencia principal de la transformación del paisaje es la lenta, pero progresiva, disminución del bosque primero y del arbolado después (figura 2).

La mayor fragilidad de los pinos a la acción antrópica tiene diversas causas (Montoya, 1986; Gil, 1991): su incapacidad de brotar les hace vulnerables a fuegos de ciclos cortos, al pastoreo, al leñeo, carboneo, fabricación de pez o extracción de teas; la roturación de sus terrenos es fácil, al no brotar de cepa o raíz; por último, sus fustes rectos son idóneos para la construcción y para el transporte una vez apeados; por lo que son buscados como vigas o andamios. La tala del pinar se veía favorecida porque la saca de tea de los montes se concedía con pocas restricciones por los señores; así los vendedores de pan o de sal podían sacar su importe en pez o en maderas, productos abundantes en las zonas serranas (Duque de Alba, 1928). Cuando la falta de caminos impedía o dificultaba la saca de maderas, siempre era posible la extracción de pez, aprovechando cualquier pino.

La localización del área potencial del pinar (Pinus sylvestris) en las zonas de pastos comunales, intensamente explotadas y quemadas periódicamente por los pastores, también favoreció su desaparición en la Sierra Pobre (figs. 3.c y 3.d). El pino albar es una especie longeva, por lo que cuando es añoso las copas están a muchos metros sobre el terreno; conformación que le permite sobrevivir a los fuegos de matorral. Basta ver como la corteza papirácea y asalmonada que recubre las partes altas de sus fustes, se detiene a pocos metros del 
suelo. En la base presenta una corteza gruesa formada por grandes placas, capaces de soportar a este nivel la acción del incendio originado por rayos y que recorren ciertas extensiones quemando pasto y matorral. Pero en los fuegos de copas, si recorren grandes extensiones y no quedan árboles supervivientes que den semillas, no hay regeneración. Si, además, tras el incendio hay pastoreo desaparecen las plántulas y con ello la continuidad del pinar. Con el tiempo, los pinares se han transformado en pinarejos $y$, finalmente, en individuos dispersos que acabarán sucumbiendo con la edad.

El melojo (Quercus pyrenaica) es una especie bien adaptada al aprovechamiento de sus formaciones ya que, de todas las especies de la zona, es la que posee mayor capacidad de rebrote vegetativo, de cepa y raíz (Ruiz de la Torre y Ceballos, 1979); capaz de soportar las podas, las cortas y el fuego. Su mayor frugalidad respecto a otras frondosas, como los robles templados, y su mayor heliofilia le permiten vivir en peores suelos y en condiciones de menor espesura. Aún así el rebrote es eliminado por desarraigo o agotamiento de la cepa, transformándose los melojares en tierras de labor, pastizales y matorrales; formaciones, las últimas, que se añadirán a las resultantes de la desaparición de los pinares. El roble albar (Quercus petraea) pudo desempeñar un papel similar al melojo en algunas zonas de más altitud, con mayores precipitaciones; prueba de ello es la presencia de grandes robles albares con signos de antiguas podas en distintas dehesas de la Sierra Pobre (Somosierra, La Hiruela, Montejo, etc.); pero su área se habrá reducido en favor del melojo, como también cabe suponer que le ocurriría al haya y al acebo. El haya tuvo que soportar cortas y podas como se aprecia en el Hayedo de Montejo y en los vecinos hayedos segovianos de Ayllón que cuentan con árboles intensamente podados (Arranz y Allué, 1993).

La especial protección de los árboles productores de fruto y de los de mayor tamaño, de gran importancia en la transformación y aprovechamiento de los montes, tiene origen antiguo. Ya en el Fuero Juzgo visigodo se establece que los pastores podían talar árboles en todo el reino siempre que respetaran a los más grandes (Klein, 1919) ${ }^{21}$. El mismo sentido tiene una Pragmática dada en 1496 por

21 Incluso cuando se tala sin la autorización del señor, sólo se penaliza la corta de manzanos, olivos y árboles de bellota; pero se extiende a otras clases de árboles en el caso de que fueran grandes (ley 1a, tit.30, lib. VIII) (Cuevas, 1925). 
condena a las demás formaciones a pasto común para el ganado. Aún así, esta protección se establece cuando tales árboles comienzan a escasear, como muestra la siguiente de las Ordenanzas de defensa de los montes del Señorío de Buitrago: ... que se haga hordenança para que como esta hasta aqui de marco, y de aqui adelante se guarde lo nuebo aunque no llegue a marco y que para leña se rramonen los árboles grandes de rrobre en terçios y fuera de terçios y que en los tercios no se pueda cortar.... Loable intento concegil de defender los árboles nuevos, pero incidiendo en los tercios, que son las tierras de los labradores. Muestra, otra vez, la protección que se da a la ganadería por monarcas y regidores, en su intento de sustituir hombres por ovejas, como denunciarán siglos después Rousseau y Jovellanos.

La transformación y conservación de los robledales, bosques mixtos al incluir otras especies como acebos, fresnos, etc., está muy ligada a su aprovechamiento pecuario y a su explotación para maderas y leña. El tipo de bosque residual modelado por las normativas fue el monte hueco, constituido por grandes robles productores de bellota, de los que se obtenía leña de las ramas secas y por podas periódicas. También debió de ser más común la presencia de estos árboles en la zona de pastos comunales y de sembradura; en ellas tampoco se permitía cortar los de más de marco. Como consecuencia de la presión del campesinado sobre los terrenos abiertos, quedaron cada vez más limitados a las dehesas, cercadas con muros de piedra, especialmente defendidas al ser necesarias para el abrigo y la alimentación del ganado de labor. Por esta razón el paisaje sufrió una parcelación progresiva; las formaciones con árboles se reducen y transforman en montes bajos o dehesas situadas en la proximidad de las aldeas; el resto del territorio se divide entre las tierras de labor y los pastos y matorrales destinados al aprovechamiento pecuario. La distribución actual de los montes de frondosas deja ver claramente esta pauta de fragmentación (figura 1).

22 «salvo los montes que fueren tan grandes y tales, que los vecinos de las dichas ciudades, villas y lugares se puedan aprovechar dellos de leña, no los cortando por pie, salvo por rama y dexando en ellos horca y pendon por donde puedan tornar á criar: $y$ que los otros montes, que no fueren tan grandes que se pueden aprovechar para bellota, y para guarecer los ganados de invierno, y todos ellos y los otros términos queden para el pasto común de los ganados». Una cédula de 1632 extendería esta ley a los montes de particulares. 
El aprovechamiento del territorio es mayoritariamente ganadero, pues tal orientación es la definida por las Ordenanzas. Los datos que se desprenden del Catastro de Ensenada (1750-1756) ${ }^{23}$, permiten ver la necesidad que tiene la oligarquía ganadera, con el señor de Buitrago a la cabeza, de controlar los montes comunes de Villa y Tierra ${ }^{24}$; aún lográndolo, tratan de incrementar el barbecho de los campos de cultivo. Este grupo constituye un pequeño porcentaje de la población (menos de un 1 por 100), pero sus rentas son desproporcionadas 25 (más de la mitad) y provienen casi exclusivamente del ganado lanar transhumante; las percibidas por la casa ducal del Infantado en el señorío de Buitrago suponen el 81 por 100. La insuficiencia de la producción agrícola, consecuencia de la poca idoneidad de muchas tierras, el elevado porcentaje de cosecha que hay que reservar para la siembra y los impuestos que se tienen que pagar, empujarán una y otra vez a los aldeanos a actuar frente al bosque, cultivando ilegalmente zonas del Común de Villa y Tierra, carboneando, descepando o haciendo leña verde en el monte público.

El paisaje actual refleja la ordenación del territorio típicamente medieval; pero reintroduciendo el pinar en zonas anteriormente forestadas a partir de matorrales de degradación, como evidencia el trabajo de Jiménez-Caballero et al. (1995) ${ }^{26}$. Estas actuaciones formaban parte del programa diseñado para reconquistar una minúscula porción del territorio español en el denominado «dilatado reino de la cabra y de la oveja» (Ximénez de Embún y Ceballos, 1939). La sombra y estratificación del pinar mejora las condiciones previas y facilitan la entrada de las frondosas umbrófilas; lo que ocurrirá de manera espontánea, si en la proximidad quedan restos del primitivo bosque:

23 El Catastro de Ensenada es analizado por el Grupo 73 bajo la dirección del profesor Miguel Artola, en la obra «La Economía del antiguo régimen. El Señorío de Buitrago»".

24 Un 67 por 100 de la superficie del señorío (Saéz Pombo com. pers., tesis doctoral en preparación).

25 Había 17 familias con más de 10.000 reales anuales, entre ellas destacan la duquesa del Infantado con 369.864 reales y otras cuatro familias con más de 60.000 reales anuales; otras 69 familias tienen ingresos entre 3.000 y 10.000 reales mientras que las 1600 restantes no superan los 3.000.

26 En la zona que estudian solamente el 1,5 por 100 de las repoblaciones lo fueron en encinares o melojares. 
un 3,6 por 100 de las repoblaciones efectuadas del área estudiadas por Jiménez-Caballero et al. (1995) presentaban melojos dispersos ${ }^{27}$.

\section{Conclusiones}

Aunque la presión en torno a las aldeas fue muy grande, la dedicación de un espacio a los bosques comunales, las dehesas, permitió la supervivencia de numerosas especies forestales, muchas de ellas de carácter templado (haya, roble albar, acebo, cerezo, avellano, etc.). Más allá de estas zonas los efectos del pastoreo impulsaron la deforestación. La mayor frugalidad del melojo frente a robles y hayas incrementó su presencia (figuras 3.b, 3.c y 3.d). Las especies templadas se refugiaron en los valles más húmedos y en las dehesas situadas a mayor altitud. Tal es el caso del haya que consiguió persistir en la dehesa del Chaparral de Montejo. Al ser una especie de sombra, el constante aclarado del bosque le perjudicaría más que al roble albar, especie de media sombra, el cual está presente, no sólo en Montejo sino también en Somosierra, en la Dehesa de La Hiruela, en Puebla de la Sierra, etc. Durante la Edad Moderna se establecen las pautas principales de organización del territorio y en los siglos posteriores se darán las últimas fases importantes de deforestación. El bosque quedará reducido progresivamente a los montes comunales, localizados por debajo de los 1.500 metros de altitud.

Las tres etapas que se han considerado en la evolución del paisaje de la Sierra Pobre (figura 2) coinciden con fases históricas también diferentes. Los cambios entre periodos consecutivos no siempre fueron drásticos, caracterizando a cada fase un modo de explotación del territorio reflejo de cierta estructura económica y social. Tras la Reconquista (1086-1366) predomina el pequeño campesinado que como nuevo colonizador extiende su acción deforestadora sobre todo el territorio, sin más limitaciones que su propia fuerza y su tecnolo-

27 Recientes ensayos de reimplantación del haya en un pinar de repoblación adyacente al Hayedo de Montejo han permitido observar la buena aptitud de estas formaciones para permitir el arraigo del haya. Así, se contabilizó solamente un 8 por 100 de marras después del primer año de plantación de hayas bajo cubierta de pinar, frente al 60 por 100 de muertes registrado en hayas plantadas bajo melojar y el 100 por 100 entre el matorral (Aranda et al., 1996). 
gía. El desarrollo de esta agricultura de montaña minifundista chocó con los límites propios del medio físico y con los cambios sociales que trajo consigo el Señorío de Buitrago (1366-1837). Con el Señorío se limita la agricultura y se protege el monte para la ganadería, y el paisaje adehesado persistirá. Sin embargo fuera de las dehesas, en el gran área de pastos comunales, la deforestación continúa y los restos de una primitiva banda de Pinus sylvestris desaparecen en la Sierra Pobre. El nuevo auge de la agricultura durante la Edad Contemporánea supuso una nueva oleada de agresiones al bosque, pero los cultivos se vieron nuevamente limitados por la pobreza del medio y se devolvieron a la ganadería una amplia extensión del territorio.

De los comentarios expuestos se deduce el riesgo que supone interpretar los bosques y la potencialidad de un territorio en base a los testigos actuales. La vegetación que hoy se observa es sólo una llave parcial para comprender los bosques del pasado. Con frecuencia, no se han incluido en los modelos sucesionales de la vegetación especies localmente extinguidas, como los pinos en la Sierra Pobre, o se han sobrevalorado otras capaces de soportar mejor la presión humana, a la par que proporcionaban aprovechamientos sostenidos de interés económico, como se ha hecho con las quercíneas. Los modelos de dinámica vegetal tienen gran importancia en la restauración de la vegetación, tan degradada en nuestro país. Por esta razón cobra gran interés conocer la historia de nuestros bosques. De entre todos los fenómenos que han acompañado a esta historia el que menos se toma en consideración es la extinción local de especies. En particular resulta llamativo que un grupo de especies, los pinos, tan denostados en los últimos años, hayan podido desaparecer de muchos lugares, incluida la Sierra Pobre, mientras las denominadas especies nobles, encinas y robles, han permanecido.

\section{Agradecimientos}

A Pedro Manuel Díaz-Fernández, Carlos Manuel Valdés y Jose Manuel Mangas Navas, por la revisión y valiosos comentarios realizados al manuscrito. 


\section{BIBLIOGRAFÍA}

AlLuÉ, J. L., 1990. Atlas fitoclimático de España peninsular y baleárica. INIA, Madrid.

Anónimo, 1833. Colección de Privilegios, Franquezas, Exenciones y Fueros concedidos a varios pueblos y corporaciones de la Corona por el Rey de Castilla. Copiados de orden de S.M. de los registros del Real Archivo de Simancas. Privilegio al Concejo del Cardoso. 28 de Julio de 1300, Madrid.

Aranda, I., Pardo, F., Gil, L. y Pardos, J.A.. (1996). Regeneración artificial de Fagus sylvativa L. en el entorno del Hayedo de Montejo de la Sierra (Madrid). Primer Congreso Ibérico Biólogos-Ambiente; Lisboa 9-11 Octubre de 1996.

ARRANZ y AlluÉ, 1993. Enumeración, descripción y cartografía de los enclaves de Fagus sylvatica L. en la vertiente segoviana del Macizo de Ayllón. Ecología , 7: 149-177.

Bravo, J. 1993. Montes para Madrid. El abastecimiento de carbón vegetal a la Villa y Corte entre los siglos XVII y XVIII. Caja de Madrid, Madrd.

CAtálogo (1864) de los Montes públicos exceptuados de Desamortización, hecho por el Cuerpo de Ingenieros de Montes en cumplimiento de lo dispuesto por Real decreto de 22 de Enero de 1862 y Real orden de la misma fecha. Provincia de Madrid. Ed. Facsímil, MAPA/ICONA, Madrid (1991).

Catálogo (1901) de los Montes y demás terrenos forestales exceptuados de la desamortización por razones de utilidad pública formado en cumplimiento a lo dispuesto en el artículo $4^{\circ}$ del Real decreto de 27 de Febrero de 1897, Imprenta de la Sucesora de M. Minuesa de los Ríos, Madrid.

CAtálogo (1932) de los Montes de utilidad pública de la provincia de Madrid, rectificado en 1932 en cumplimiento de lo dispuesto en la Orden Ministerial de 24 de Abril de 1931. Ministerio de Agricultura, Industria y Comercio, Madrid.

Ceballos, L., López Vallejo, L., Pardos, J.A. y Úbeda, J. 1966. Mapa forestal de España. Escala 1:400.000. Ministerio de Agricultura, Madrid.

Corominas, J. y Pascual, J. 1981. Diccionario crítico etimológico castellano hispano , Vol $I V$. Ed. Gredos, Madrid.

Costa, J. 1911. La fórmula de la agricultura española, Tomo I: Agricultura armónica y Politica hidráulica. En: Obras completas de Joaquín Costa, Vol. I. Biblioteca Joaquín Costa, Madrid.

Costa, M., García Antón, M., Morla, C. y Sáinz, H. 1990. La evolución de los bosques de la Península Ibérica: una interpretación basada en datos paleobiogeográficos. Ecologia, Fuera de Serie, 1: 31-58.

Cuevas DEL REY, E. 1925. Indice legislativo forestal. Imprenta viuda de M. Aguarón, Huesca.

Duque De AlBa. 1928. Relaciones de la Nobleza con sus pueblos y plan de una codificación de las Ordenanzas dadas por los Señores a sus vasallos. Tipografía de la revista de Archivos, Madrid.

FERnÁNDEZ, M. 1966. Fuentes para la historia de Buitrago y su tierra. 2 vols., Madrid.

FERnANDEZ, M. 1980. Buitrago y su tierra (algunas notas históricas), Madrid.

Fernandez-Galiano, E. 1990. Pasado, presente y futuro de los bosques de la Península Ibérica. Acta Botánica malacitana, 15: 135-143.

Fernandez Montes, M., 1990. Cultura tradicional en la comarca de Buitrago. PAMAM, Comunidad de Madrid, Madrid.

Fillat, F., 1993. Recursos agrarios de montaña: alternativas para el Pirineo español. Ecosistemas , 7: 42-47.

Franco, F. 1995. Estudio palinológico de turberas holocenas en el Sistema Central español: reconstrucción paisajistica y acción antrópica. Tesis doctoral, Universidad Autónoma, Facultad de Ciencias, (inédita), Madrid.

Garcia Latorre, J. y Garcia LatorRe, J. 1996. Los bosques ignorados de la Almería ári- 
da. Una interpretación histórica y ecológica, pp: 99-126. En A. Sánchez Picón, ed.: Historia y medio ambiente en el territorio almeriense. Universidad de Almería, Servicio de publicaciones, Almería.

GiL, L.1991. Consideraciones históricas sobre Pinus pinaster Aiton en el paisaje vegetal de la Península Ibérica. Estudios geográficos, 202: 5-27.

GIl GARCía, 1992. Dinámica de la paleovegetación en el sector oriental del Sistema Central durante el Holoceno en base al análisis polinico. Implicaciones climáticas. Tesis doctoral, Univ. Alcalá de Henares (inédita), Alcalá de Henares (Madrid).

GonZÁlez, J. 1960. El Reino de Castilla en la época de Alfonso VIII. 3 vols. CSIC, Madrid.

Grupo 73, 1973. La economía del Antiguo Régimen. El Señorio de Buitrago. Universidad Autónoma, Madrid.

Hernandez Bermejo, J. E. y SÁinz Ollero, H. 1978. Ecología de los hayedos meridionales ibéricos: El Macizo de Ayllón. MAPA, Madrid.

Huntley, B., y BiRks, H. J. B. 1983. An atlas of past and present pollen maps for Europe; 0-13.000 years ago. Cambridge University press, Cambridge.

INFORME (1855). de la Junta Facultativa de Ingenieros de Montes sobre los montes que conviene exceptuar de la desamortización conforme a lo mandado en el artículo $2^{\circ}$, párrafo 6, de la ley de 1 de mayo de 1855. MAPA/ICONA, Madrid (1987).

Jiménez-Caballero, S., Barrera, I., Elena, R. y Castejón, M. 1995. Evaluación de los cambios de la cubierta vegetal en un sector del macizo de Ayllón (Sistema Central, España), mediante métodos cartográficos. Ecología, 9: 165-175.

KLeIN, J. 1919. La Mesta. Alianza Ed., Madrid.

Luis López, C. 1987. Documentación medieval del Archivo Municipal de Piedrahíta (1372-1549). Fuentes Históricas Abulenses, 3, vila.

MADARIAGA, J. A. 1909. El hayedo más meridional. Revista de Montes, 788: 769-775.

Madoz, P. 1848. Madrid, Audiencia, Provincia, Intendencia, Vicaría, Partido y Villa. Ed. Facsímil, Ed. baco, Madrid (1981).

Mancebo, J. M., Molina, J. R. y Camino, F. 1993. Pinus sylvestris L. en la vertiente septentrional de la Sierra de Gredos (vila). Ecologia, 7: 233-245.

MANGAS, J. M. 1981. El régimen comunal agrario de los concejos de Castilla. MAPA, Serie Estudios, Madrid.

Martínez Díez, G. 1983. Las Comunidades de Villa y Tierra de la Extremadura Castellana. Editora Nacional, Madrid.

Montoya, J. M.1986. Ecología y pinares. Bol. Est. Central de Ecología, 15 (30): 19-24.

PASTOR DE Togneri, R. 1970. La lana en Castilla y León antes de la organización de la Mesta. Moneda y Crédito, 112: 47-55.

Ruiz del CASTILlo, J. 1993 Análisis palinológico de nueve perfiles turbosos cuaternarios en el sector oriental del Sistema Central español. Estudio paleoecológico regional. Tesis doctoral, Universidad Complutense de Madrid, Facultad de Geología (inédita), Madrid.

Ruiz DE LA TORRe, J. 1990. Distribución y características de las masas forestales españolas. Ecología, Fuera de serie, 1: 11-30.

Ruiz de la ToRRe, J. y Ceballos, L. 1979. Árboles y arbustos de la España peninsular. ETSI de Montes, Madrid.

SAez, E. 1953. Los Fueros de Sepúlveda. Segovia

SÁtz SÁnchez, C. 1991. Colección diplomática de Sepúlveda. Segovia.

SANZ, J. 1985. La historia contemporánea de los montes públicos españoles, 1812-1930. Notas y reflexiones (I), pp: 193-228. En R. Garrabou y J. Sanz, eds.: Historia agraria de la España contemporánea 2. Expansión y crisis.

VÁZQUEZ 1992. Evolución paisajística durante el cuaternario reciente en la zona central y oriental de la Sierra de Guadarrama a partir de análisis polinicos. Tesis doctoral, Universidad de Alcalá de Henares (inédita), Alcalá de Henares (Madrid). 
VillaR, L. y García-Ruiz, J. M. 1977. Explotación del territorio y evolución de pastos en dos valles del Pirineo occidental. Publ. Centro Pir. Biol. Exp., 8: 143-163.

Ximénez de Embúm, J y Ceballos, L. 1939. Plan general para la repoblación forestal de España. Comisión del plan general de repoblación forestal, pp: 7-388. En: Tres trabajos forestales. Homenaje a Luis Ceballos. 1996. Ed. Organismo Autónomo Parques Nacionales, Madrid.

Resumen: La transformación del paisaje en la Sierra Pobre de Madrid. influencia de la agricultura y la ganadería en la extincion local de los pinares. En el presente trabajo se repasan los principales cambios ocurridos en el paisaje forestal de la Sierra Pobre de Madrid desde la Reconquista. El destino de las distintas especies arbóreas fue bastante diferente debido tanto a razones ecológicas como históricas. En este sentido las formaciones de pinar desaparecieron casi en la totalidad del área de estudio mientras que gran parte de los robledales han permanecido hasta la actualidad aunque reducidos y transformados. Finalmente se señala el riesgo de no considerar los factores históricos en la interpretación de los bosques. Por esta causa pueden no incluirse en los modelos de dinámica vegetal especies localmente extinguidas o sobrevalorar a las especies menos afectadas por la intervención antrópica.

Summary Forest landscape transformations in Sierra Pobre of Madrid: Influence of agriculture and livestock in local extintion of pine forest. This paper describes the main changes in forest landscape of Sierra Pobre of Madrid after Reconquista. Forest tree species has a different destiny because of both ecological and historical reasons. In this respect the pine formations disappear in almost all study area, whereas many oak forests remained although reduced and altered. Finally the risk of ignoring history in forest interpretation is pointed out. For this reason some local extinct species can not be included in plant succession models, while others can be more valorated because they have been the less influenced by man activity.

Résumé: La transformation du paysage dans la Sierra Pobre de Madrid: influence de l'agriculture et de l'élevage dans la extinction local des pinèdes. Dans le prèsent travail sont analyseés les principaux changementes qui ont eu lieu dans le paysage forestier de la Sierra Pobre de Madrid depuis la Reconquête (XII ème . siecle). Les raissons historiques et écolgiques ont eu une influence différent sur chaqu'éssence forestier: les pinèdes ont presque disparu, tandis qu'une grande partie des rouvraies ont resté jusqu'au prèsent, bien que réduites et transformés. On remarque le risque de ne pas prendre en consideration les facteurs historiques dans l'interprétation des fôrets: des essences disparues ne sont pas prises en consideration dans les modéles de dynamique vègètale, vis à vis de l'importance donné aux essences adaptées a l'action de l'homme. 